\title{
INCIDENCIA DE LAS LEYES 39 Y 40/2015 EN LA RESPONSABILIDAD PATRIMONIAL POR ASISTENCIA SANITARIA EN SUPUESTOS DE GESTIÓN PRIVADA ${ }^{1}$
}

\author{
Miriam Cueto Pérez \\ Profesora titular de Derecho Administrativo \\ Universidad de Oviedo
}

\begin{abstract}
RESUMEN
Este trabajo tiene como objeto analizar la incidencia que las nuevas Leyes 39/2015 y 40/2015 pueden tener en el ámbito de la responsabilidad por asistencia sanitaria en el marco del SNS, tanto cuando se gestiona por personificaciones jurídico-privadas como cuando se gestiona por medio de un contratista de la Administración.
\end{abstract}

Palabras clave: responsabilidad patrimonial; asistencia sanitaria; gestión privada.

\begin{abstract}
The main aim of this paper is to analyse the impact of Laws 39 and 40/2015 on claims for damages due to Health assistance in the framework of NHS, when the health assistance is provided either by private institutions or by a contractor of Public Administration.
\end{abstract}

Keywords: health assistance; private management.

\footnotetext{
1 Este trabajo se enmarca en el Proyecto DER2015-68256R «Respuestas jurídicas ante los riesgos derivados de las transformaciones de la Administración: demandas sociales y protección del e-ciudadano».
} 


\section{SUMARIO}

I. Planteamiento general.- - II. Diferentes fóRmulas de gestión de la asistencia sanitaria en el marco del Sistema Nacional de Salud: 1. Gestión indirecta de la asistencia sanitaria. 2. Gestión a través de personificaciones jurídicoprivadas.-III. RESPONSABILIDAD PATRIMONIAL EN SUPUESTOS DE GESTIÓN PRIVADA: 1. Responsabilidad de sociedades mercantiles y fundaciones por la prestación de asistencia sanitaria. 2. Responsabilidad de la Administración por la gestión indirecta de la asistencia sanitaria: A) Responsabilidad de la Administración derivada los servicios públicos concedidos. B) La responsabilidad patrimonial en supuestos de gestión indirecta de la asistencia sanitaria.

\section{Planteamiento general}

En los últimos años, las fórmulas de gestión privada en la asistencia sanitaria han entrado con fuerza en el ámbito del Sistema Nacional de Salud, amparadas por la pregonada eficacia de lo privado frente a lo público e impulsadas por las circunstancias económicas actuales. La crisis económica y cierta incertidumbre ya anterior sobre la viabilidad del sistema habían puesto sobre la mesa la imposibilidad de mantener nuestro sistema sanitario en los mismos términos en los que se había configurado. El derecho a la protección de la salud contemplado en el art. 43 de la Constitución española de 1978 (CE) señala que compete a los poderes públicos organizar y tutelar la salud pública a través de medidas preventivas y de las prestaciones y servicios necesarios, siendo la Ley la encargada de establecer los derechos y deberes de todos al respecto. Por ello, y como premisa, es necesario ser conscientes de que el contenido de ese derecho, encuadrado en los principios rectores de la política económica y social ${ }^{2}$, vendrá determinado por las circunstancias sociales, políticas y económicas de cada momento, y que será el legislador el que determine su extensión material, ampliando o reduciendo sus prestaciones, por ejemplo, ante una imposibilidad económica de afrontar el gasto sanitario de los servicios existentes, tal y como ya ha ocurrido con la promulgación del Decreto-Ley 16/2012, de 20 de abril, de medidas urgentes para garantizar la sostenibilidad del Sistema Nacional de Salud ${ }^{3}$.

2 J. M. Fernández Pastrana (1984), El servicio público de la sanidad: el marco constitucional, Madrid: Civitas, págs. 55 y ss.

3 Sobre la reversibilidad de las prestaciones sanitarias tempranamente E. CoBreros MenDAZONA (1988), Los tratamientos sanitarios obligatorios y el derecho a la salud, IVAP, págs. 173 y ss.; S. Muñoz Machado (1995), La formación y la crisis de los servicios sanitarios públicos, Alianza Editorial, págs. 146-159; J. PEMÁn Gavín (1989), Derecho a la salud y Administración sanitaria, Bolonia: Publicaciones del Real Colegio de España, pág. 89; J. L. Beltrán Aguirre (1994), «Prestaciones sanitarias del Sistema Nacional de Salud: aspectos jurídicos», en Dere- 
Junto al alcance y extensión de las prestaciones, las formas de gestión tienen también su importancia en el desarrollo del derecho a la protección de la salud 4 . La Ley 14/86, de 25 de abril, General de Sanidad, (LGS), diseñó un Sistema Nacional de Salud (SNS) y configuró la asistencia sanitaria como un servicio público ${ }^{5}$, permitiendo fórmulas de gestión indirecta (principalmente los conciertos sanitarios) y garantizando igualmente la libertad de empresa, por lo que estaríamos ante un servicio público impropio, donde tiene cabida plenamente la iniciativa privada. Con posterioridad a esta Ley, se llevó a cabo la transferencia de competencias a favor de las CC.AA. y estas han ido dictando sus propias leyes autonómicas en la materia, en desarrollo de la normativa básica estatal concretada en importantes normas que han ido definiendo nuestro SNS, como la Ley 41/2002, de 14 de noviembre, de autonomía del paciente y de derechos y obligaciones en materia de información y documentación clínica, la Ley 16/2003, de 28 de mayo, de cohesión y calidad del Sistema Nacional de Salud, la Ley 44/2003, de 21 de noviembre, de ordenación de las profesiones sanitarias, la Ley 55/2003, de 16 de diciembre, del Estatuto marco del personal estatutario de los servicios de salud, y más recientemente, la Ley 33/2011, de 4 de octubre, General de Salud Pública. De este conjunto de normas, se debe destacar, en relación con el objeto de estudio de este trabajo, el reconocimiento de una serie de derechos a los ciudadanos como pacientes frente a los servicios sanitarios, derechos que, como señala el profesor Pemán Gavín, «se refieren no tanto al contenido mismo de las prestaciones como al modo en que tales prestaciones son efectivamente realizadas, con fijación por tanto del marco jurídico básico en el que han de desenvolverse las relaciones

cho y salud, 2, 2, págs. 91 y ss.; D. LOPERENA Rota (2012), «La irreversibilidad de los Derechos sociales», en Revista Aranzadi Doctrinal, 9; J. Ponce Solé (2013), El derecho y la (ir) reversibilidad limitada de los derechos sociales de los ciudadanos. Las líneas rojas constitucionales a los recortes y la sostenibilidad social, Madrid: Ed. INAP, págs. 68-69; J. CANTERo MARTínez (2013), «Las políticas sanitarias regresivas», en Derecho y Salud, 23, págs. 107 y ss.; V. AguAdo I CudoLA (2014), «Derecho a la protección de la salud y exclusión de la asistencia sanitaria: la crisis económica como pretexto para la limitación del acceso a los servicios y prestaciones del estado del bienestar», en RVAP, 99-100, págs. 87 y ss. Recientemente, en E. M. MEnÉndez SEBASTiáN (2016), La Administración al servicio de la Justicia social, Iustel, págs. 109 y ss.

4 Baste recordar el movimiento social que se ha generado en contra de las intenciones privatizadoras del Gobierno de la Comunidad de Madrid y que han acabado finalmente con la renuncia a seguir adelante con el proceso.

${ }^{5}$ La configuración de la asistencia sanitaria como un servicio público no planteó mayores dudas, vid. F. Garrido Falla (1981), El modelo económico en la Constitución, vol. I, Madrid: IEE; J. M. FERnÁNDEZ PAStrana (1984) y M. Beato EsPejo (1989), «El sistema sanitario español: su configuración en la Ley General de Sanidad», en RAP, 119, pág. 403; A. Palomar OlmedA (2013), «El modelo de sanidad pública: consideraciones de carácter introductorio y generales sobre la conformación de un servicio público esencial», en Tratado de Derecho sanitario $(A A V V)$, vol. I, Aranzadi, págs. 109 y ss. 
entre los servicios de salud y los ciudadanos pacientes ${ }^{6}$, derechos que tienen sus obligaciones correlativas y cuyo incumplimiento generará la consiguiente responsabilidad de los poderes públicos, cuando del mismo se deriven lesiones para los particulares que estos no tengan el deber jurídico de soportar.

El principio de responsabilidad patrimonial de las administraciones públicas consagrado en el art. 106.2 de la CE otorga a los particulares un derecho que constituye la pieza de cierre del sistema de garantías frente a la actuación administrativa. Esta pieza, sin embargo, se puede ver alterada por las diferentes fórmulas de gestión de servicios sanitarios implantadas, tanto en lo que se refiere a la asistencia sanitaria como a los servicios parasanitarios que acompañan la atención de los pacientes ${ }^{7}$. La opción por una u otra fórmula de gestión no resulta inocua para el sistema de responsabilidad de la Administración titular del servicio y por ello el legislador, ante la complejidad, la conflictividad y las peculiaridades de este servicio público, trató de poner fin a las dudas existentes sobre el régimen jurídico aplicable (administrativo-objetivo/ civil-culpabilístico), sobre el procedimiento de reclamación y sobre el orden jurisdiccional competente (tres órdenes jurisdiccionales han llegado a conocer sobre esta materia, el orden civil, el social y el contenciosoadministrativo, además del penal). En cuanto al derecho aplicable, el mismo se clarificó por medio de la DA duodécima de Ley 30/92, de 26 de noviembre, de Régimen Jurídico de las Administraciones Públicas y del procedimiento administrativo común (Ley 30/92), incluida tras su reforma por la Ley 4/99, de 13 de enero, y respecto a la jurisdicción competente se cerró la cuestión con la modificación de la Ley 29/98, de 13 de julio, de la jurisdicción contencioso-administrativa (LJ), art.2. e) y de la Ley Orgánica 6/1985, de 1 de julio, del Poder Judicial (art. 9.4), que extienden la competencia jurisdiccional del orden contencioso a las demandas de responsabilidad patrimonial en las que concurren en la producción del daño particulares o se demande a la aseguradora ${ }^{8}$.

Sin embargo, tras estas clarificaciones aún la jurisprudencia ha dudado en algunos supuestos tanto sobre el derecho aplicable como sobre la jurisdicción competente ${ }^{9}$, de hecho, como se explicitará más adelante,

6 J. Pemán Gavín (2005), Asistencia sanitaria y Sistema Nacional de Salud, Granada: Editorial Comares, pág. 17.

7 L. Tolivar Alas (2007): "Derechos de los usuarios y pacientes ante la gestión privada de servicios sanitarios", Derecho y Salud, vol. 15, número extraordinario, pág. 44.

8 Modificadas por LO 19/2003, de 23 de diciembre.

9 A. YañEz DE ANDRÉs (2014): "La responsabilidad de la Administración por la prestación de asistencia sanitaria en un contexto de crisis económica. Perspectiva de un abogado", Revista Aranzadi Doctrinal num.11/2014 
en los últimos tiempos se ha considerado que la responsabilidad por los daños derivados de la asistencia sanitaria prestada por las mutualidades de funcionarios de nuevo debía ser entendida como una responsabilidad civil sometida a las previsiones del CC, por mediar un concierto entre estas y las empresas que prestan la asistencia. Igualmente, la construcción y gestión de centros sanitarios usando fórmulas contractuales, como la concesión de obra pública, ha vuelto a generar dudas sobre el régimen jurídico de la responsabilidad derivada de esa asistencia sanitaria. Por todo ello, la supresión del contenido de la DA duodécima de la Ley 30/92, en la Ley 39/2015, de 1 de octubre, de Procedimiento Administrativo Común de las Administraciones Públicas y en la Ley 40/2015, de 1 de octubre, de régimen jurídico del sector público, nos alerta de que nuevos planteamientos pueden estar por llegar y que nuevos peligros acechan a esta unidad en el régimen de responsabilidad patrimonial por asistencia sanitaria, tanto en lo que se refiere al derecho aplicable como a la jurisdicción competente para conocer las reclamaciones de los pacientes cuando la asistencia sanitaria se preste por medio de fórmulas de gestión privada. El análisis de las reclamaciones por asistencia sanitaria en este nuevo marco normativo será el principal objeto del presente trabajo.

\section{Diferentes fóRmulas de gestión de la ASISTENCIA SANITARIA EN EL marco del Sistema Nacional de Salud}

Desde la publicación del Real Decreto Ley 10/1996, de 17 de junio, sobre habilitación de nuevas formas de gestión del Sistema Nacional de Salud, y más tarde de la Ley 15/97, de 25 de abril, se estableció la posibilidad de que, garantizando y preservando en todo caso su condición de servicio público, en el ámbito del SNS la gestión y administración de los centros, servicios y establecimientos sanitarios de protección de la salud o de atención sanitaria o sociosanitaria pudiese llevarse a cabo directa o indirectamente a través de la constitución de cualesquiera entidades de naturaleza o titularidad pública admitidas en derecho (el Decreto Ley hablaba en cambio de cualesquiera entidades admitidas en derecho) e igualmente la prestación y gestión de los servicios sanitarios y socio-sanitarios podrá llevarse a cabo, además de con medios propios, mediante acuerdos, convenios o contratos con personas o entidades públicas o privadas, en los términos previstos en la LGS. Siguiendo esta estela, la Ley 50/1998, de 30 de diciembre, en su art. 111 reguló el régimen de las fundaciones públicas sanitarias, como una nueva categoría de organismos públicos y el RD 29/2000, de 14 de enero, sobre nuevas 
formas de gestión del Instituto Nacional de la Salud, estableció un régimen jurídico para estas personificaciones, insistiendo en que deberían garantizar y preservar la condición de servicio público. Esta regulación no contemplaba, sin embargo, la segunda modalidad de la previsión de la Ley 15/97, por la que se permitía la prestación a través de convenios o contratos con personas o entidades públicas o privadas. En un primer momento se puso el acento y la preocupación en la constitución de fundaciones, consorcios y sociedades mercantiles para la gestión de servicios sanitarios, pero lo cierto es que estas fórmulas en los últimos tiempos han sido claramente superadas y lo que ha imperado es la gestión indirecta a través de diversas modalidades de contratación que han superado claramente las previsiones de la LGS sobre los conciertos ${ }^{10} \mathrm{y}$ convenios singulares allí regulados (arts. 66-67 y 90), fórmula tradicional en la gestión de servicios sanitarios, que no ha generado nunca el rechazo surgido frente a las nuevas opciones planteadas ${ }^{11}$.

\section{Gestión indirecta de la asistencia sanitaria}

Los modelos de colaboración público-privada y las reformas organizativas y de gestión en el SNS ${ }^{12}$, en especial las destinadas a buscar fórmulas para la construcción y gestión de infraestructuras sanitarias, han generado numerosas dudas sobre su oportunidad y acierto en el ámbito de la asistencia sanitaria, como ha ocurrido con la concesión del servicio público sanitario (incluyendo normalmente obras de primera instalación) o la concesión de obra pública, cuya configuración legal chirría con la propia naturaleza de la asistencia sanitaria, servicio muy costoso, más si tenemos en cuenta que se configura con carácter universal y gratuito, que existe un progresivo envejecimiento de la población y un crecimiento constante de la demanda de servicios por parte de la misma.

La concesión se realiza por el empresario a su riesgo y ventura y está pensada principalmente para actividades de claro contenido económico. La utilización de la concesión en el ámbito sanitario se ha producido en la mayor parte de los supuestos cuando va acompañada de obras de primera instalación, es decir, cuando el contrato incluye junto a la gestión de la

10 En el anteproyecto de Ley de Contratos del Sector público se suprime este característico contrato administrativo reconduciéndose a una única modalidad que se denomina contrato de concesión de servicios.

11 A. Domínguez Simón (2011), «El contrato de gestión de servicio público en la modalidad de concierto», en Derecho y Salud, 21, extraordinario, págs. 141 y ss.

12 J. J. Martín Martín (2003), «Nuevas fórmulas de gestión en las organizaciones sanitarias», Fundación Alternativas, Documento de Trabajo, 14. 
asistencia sanitaria la construcción del hospital o del centro o centros sanitarios precisos para la prestación. Las infraestructuras en estos casos se construyen sobre suelo público y las mismas, una vez construidas, pasan a ser de titularidad pública y se integran desde el primer momento en la red de hospitales públicos. Esta posibilidad hace que en ocasiones sea difícil diferenciar los supuestos en los que estamos ante concesiones de gestión de servicios con obras accesorias al mismo o ante un contrato de concesión de obra pública, en el que la obra constituye la razón de ser del contrato. En virtud de estos contratos administrativos la empresa concesionaria (que suele ser una UTE del sector) se compromete a financiar y construir el centro hospitalario, así como a su posterior gestión no limitada a los servicios de carácter parasanitario sino también a la asistencia sanitaria. En estos casos, la prestación de la totalidad de los servicios que ofrece toda institución hospitalaria pública es asumida por el sector privado y la financiación pública se articula a través de un sistema de pago capitativo, en virtud del cual la comunidad autónoma paga un tanto anual al concesionario por cada uno de los habitantes incluidos en la zona sanitaria a la que da cobertura el hospital.

En el ámbito sanitario la concesión de obra pública ha permitido financiar la construcción de nuevas infraestructuras hospitalarias por parte de las administraciones autonómicas, debiendo luego proceder al abono de las mismas mediante la entrega de la explotación económica de la infraestructura al contratista, y en la mayor parte de los casos, junto a la entrega de un canon. Desde el punto de vista jurídico las dudas surgen debido a que la actividad principal de la infraestructura hospitalaria es la asistencia sanitaria y que esta en el marco del SNS no es susceptible de explotación económica, lo cual cuestiona claramente la utilización de esta modalidad contractual para la gestión indirecta de servicios sanitarios $^{13}$. El uso del contrato de concesión de la obra pública se ha considerado por la doctrina inadecuado para la construcción y gestión de infraestructuras hospitalarias cuya función principal es la prestación de servicios sanitarios no susceptibles de explotación, ya que los pacientes no pagan una tarifa ${ }^{14}$, siendo la Administración en realidad el único

13 La JCCA también se ha manifestado en contra de que se pueda utilizar el contrato de concesión de obra pública si el resultado de la obra no es susceptible de explotación económica, por todos su Informe 61/2003 sobre la construcción de un edificio para albergar los servicios centrales de la Universidad de Burgos.

14 F. J. Villar Rojas (2006), «La concesión administrativa de obra pública como nueva forma de gestión de servicios sanitarios», en Derecho y Salud, vol. 14, número extraordinario, págs. 1-16 y en (2007), «La concesión como modalidad de colaboración privada en los servicios sanitarios y sociales», en RAP, 172, págs. 141 y ss.; L. Tolivar Alas (2007: 43 y ss.). Con carácter general sobre la concesión de obra pública, vid. A. RuIz OJEDA (2006), La concesión de obra pública, Thomson-Civitas, y P. VALCÁRCEL FERnÁNDEZ (2006), Ejecución y financiación de obras 
usuario, que retribuiría junto con la explotación de la infraestructura por períodos largos de tiempo que pueden alcanzar los cuarenta años (art. 268 del TRLCSP) para fines complementarios (conservación, mantenimiento integral del edificio, lavandería, catering, limpieza, desinfección, vigilancia, gestión de residuos sanitarios...) y para servicios comerciales (cafetería, tiendas, aparcamiento, televisiones de las habitaciones), por medio del abono de un canon, lo que implica que no hay una verdadera asunción de riesgos de explotación por el concesionario ${ }^{15}$. Una vez finalizada la concesión, el inmueble revertiría a la Administración sin derecho a indemnización (art. 272 del TRLCSP).

Los gobiernos autonómicos responsables de la prestación de la asistencia sanitaria han buscado desde hace tiempo alternativas para la financiación de nuevos hospitales, ante el enorme esfuerzo presupuestario que suponía y la necesidad de cumplir los límites de endeudamiento para satisfacer las exigencias de estabilidad presupuestaria. Esta opción, siendo perfectamente legítima, pecó de ingenua, ya que el sector privado, si bien podía contribuir a la financiación de las infraestructuras, lo haría siempre a cambio del beneficio empresarial y, por las razones expuestas, cuesta visualizar el interés económico que pueda haber en la gestión de la asistencia sanitaria en el marco del SNS para el sector privado ${ }^{16}$. Las posibilidades reales de mejorar el coste del servicio, ofreciendo la misma calidad y el mismo nivel de cobertura, han fracasado ya en países pioneros como el Reino Unido ${ }^{17}$. La gestión privada, en principio más eficiente que la pública, también ha sido deficitaria, viéndose los poderes públicos en último término obligados a absorber dicho déficit como últimos responsables de la continuidad del servicio de asistencia sanitaria a los ciudadanos, con lo cual la alabada eficiencia del modelo queda puesta en entredicho ${ }^{18}$.

públicas. Estudio de la obra pública como institución jurídico-administrativa, Fundación Caixagalicia / Thomson-Civitas, prólogo de J. L. Piñar Mañas; F. REYes SANTías (2010), «Concesión de obra y financiación de hospitales: análisis jurídico para España», en Revista de Derecho, 34, págs. 116 y ss.

15 En Madrid ya se han reclamado cantidades por parte de las concesionarias vinculadas en unos casos a la interpretación de los criterios retributivos o al volumen de servicios objeto de retribución. SSTSJ de Madrid de 10 de junio de 2015, 11 de mayo de 2015 y 15 de octubre de 2014.

16 A. Menéndez ReXach (2008), «La gestión indirecta de la asistencia sanitaria púbica. Reflexiones en torno al debate sobre la privatización de la sanidad», en Revista Administración Sanitaria, 6 (2), págs. 269-296.

17 D. Larios Risco y V. Lomas Hernández (2007), «Modelos de colaboración público-privada para la construcción y gestión de infraestructuras sanitarias», en Derecho y Salud, 15, 2, págs. 291-292.

18 En varios supuestos la Administración titular del servicio ha tenido que salir en «ayuda» de los concesionarios. El hospital de Alzira, paradigma del modelo, se puso en funcionamiento en 1999 generando en sus primeros años de funcionamiento pérdidas importantes, lo que mo- 
En España estas formas de gestión han recibido el respaldo del TC en su sentencia $84 / 2015$, de 30 de abril, sentencia que se pronuncia sobre las medidas jurídicas adoptadas para poner en marcha las acciones contempladas en el llamado Plan de Medidas de Garantía de la Sostenibilidad del Sistema Sanitario Público de la Comunidad de Madrid de $2012^{19}$. En el mismo se contemplaban una serie de actuaciones que tenían como primera finalidad el ahorro en el sistema, tal como expresamente se recoge en el Plan $^{20}$. La Ley 8/2012, de 28 de diciembre, de Medidas Fiscales y Administrativas de la Comunidad de Madrid, concretó en los arts. 62 y 63 estas previsiones, siendo recurrido su contenido ante el TC. El art. 62 de forma abierta habilitaba al Servicio Madrileño de Salud para que pudiese, de acuerdo con lo establecido en el artículo único de la Ley 15/1997, de Habilitación de Nuevas Formas de Gestión del Sistema Nacional de Salud, «adjudicar contratos para la gestión del servicio público de asistencia sanitaria especializada» de seis hospitales de la Comunidad de Madrid ${ }^{21}$. En su FJ séptimo el TC da por buena esta posibilidad y rechaza que el modelo de Seguridad Social configurado en la CE no permita fórmulas de gestión de la asistencia sanitaria por entidades privadas, recordando lo ya señalado en sus sentencias anteriores 37/94, de 10 de febrero, y 213/2005, de 30 de abril. Así, considera que el art. $41 \mathrm{CE}$ no exige que el mantenimiento de un régimen público de Seguridad Social requiera necesariamente y en todo caso un sistema de gestión pública directa. El sistema no quedaría cuestionado "por la incidencia en él de fórmulas de gestión o responsabilidad privadas, de importancia relativa en el conjunto de la acción protectora de aquel». Para afirmar que «a partir de estas premisas, en

tivó que la Generalidad Valenciana en 2003 tuviese que tomar medidas. Se convocó un nuevo concurso con nuevas condiciones y se añadió al objeto del contrato (la atención hospitalaria y especializada) la atención primaria de toda la zona modificándose la duración de la concesión de 10 a 15 años. El pago por habitante se aumentó de forma considerable (de 262 euros a 379). Con el hospital de Manises volvió a ocurrir lo mismo en 2012, sin que en este caso la Generalidad Valenciana procediera a restaurar el equilibrio económico-financiero del contrato mediante una nueva inyección de dinero público, si bien el precio que se abonaba por persona comenzó siendo de 494,72 euros para el ejercicio 2006, cantidad que para el año 2012 quedó fijada en 639,1 euros. Desde la dirección del hospital se anunciaron pérdidas por un importe de 76 millones de euros.

19 Con anterioridad la STS de 20 de diciembre de 2005 también había validado esta opción apoyándose en las posibilidades de gestión indirecta de la asistencia sanitaria en el marco del SNS al amparo del Decreto Ley 11/96 y de la Ley 15/97, en relación con el modelo Alzira. RJ 2006/ 4212. Confirma la sentencia del TSJ de Valencia de 20 de diciembre de 2000.

20 «Lo primero y más importante que se pretende conseguir es un importante ahorro, en la misma medida en que han disminuido nuestros ingresos». Documento completo en www. madrid.org,

21 M. Domínguez Martín (2013), «Formas de gestión indirecta de los servicios sanitarios y "privatización" de la sanidad pública (especial referencia al plan de medidas de la Comunidad de Madrid», en RJUAM, 27, págs. 111-142; también en (2013), «Formas de gestión del SNS: de la LGS a las fórmulas de colaboración público-privadas», en Tratado de Derecho Sanitario, op. cit. págs. 401-434. 
este caso no puede concluirse que la solución organizativa plasmada en el art. 62 de la Ley 8/2012, de medidas fiscales y administrativas de la Comunidad de Madrid, transgreda los límites relativos definidos por nuestra doctrina». Además, incide en que se afecta solamente a la asistencia sanitaria especializada que se presta en seis hospitales de la Comunidad de Madrid (Hospitales Infanta Cristina, Infanta Sofía, Infanta Leonor, Sureste, Henares y Tajo), de alguna forma dejando entrever que solamente una parte del sistema se verá afectada y que no tendría la suficiente entidad como para alterar la consideración del conjunto. El TC incide también en que: «La posible apertura a formas de gestión y responsabilidad privada se lleva a cabo preservando en todo caso la titularidad pública del servicio» y recuerda que «la norma recurrida, de hecho, apoya la previsión en lo dispuesto en el ya mencionado artículo único de la Ley 15/1997, de 25 de abril, sobre habilitación de nuevas formas de gestión del Sistema Nacional de Salud, que, entre otras posibilidades, dispone que la prestación y gestión de los servicios sanitarios podrá llevarse a cabo mediante acuerdos, convenios o contratos con personas o entidades públicas o privadas». Esta Ley, a juicio del TC, «vino a disipar cualquier duda acerca de la posibilidad de acudir a técnicas de gestión indirecta del servicio público de la sanidad». Finalmente, se argumenta que la definición de las prestaciones a las que tienen derecho los ciudadanos queda en manos, en todo caso, de los poderes públicos y que la financiación seguirá siendo pública, garantizándose conforme al art. 62 «los adecuados niveles de calidad, atención y derechos de los usuarios». De los extractos realizados podemos señalar que para el TC parece relevante el alcance y el volumen de la gestión sanitaria objeto de gestión privada, de forma que el carácter público del conjunto no se desvirtúe por una gestión parcial privada de determinados ámbitos, también resulta ser crucial la titularidad pública del servicio y la definición de las prestaciones a las que tengan derecho en cada momento los ciudadanos por parte de la Administración; finalmente, se insiste en el deber de preservar la calidad, los niveles de atención y los derechos de los pacientes sea cuál sea la forma de gestión.

De igual forma, el TC rechaza que se atente contra el principio de igualdad al prestar una parte de la asistencia sanitaria mediante fórmulas de gestión indirecta y otra de forma directa y, por lo tanto, situando a los ciudadanos en una diferente posición en función del hospital en el que reciban la asistencia sanitaria. Entiende el TC que el precepto «por sí solo, no establece ninguna diferencia de trato en cuanto al contenido, alcance o calidad de la prestación sanitaria que hayan de recibir los ciudadanos asignados a esos seis hospitales». Por el contrario, la propia norma recurrida se encarga de precisar que en la contratación adjudicada se 
garantizarán «los adecuados niveles de calidad, atención y derechos de los usuarios», derechos entre los que se encuentra la garantía de accesibilidad de todos los usuarios del Sistema Nacional de Salud a las prestaciones sanitarias «en condiciones de igualdad efectiva» (art. 23 de la Ley 16/2003, de 28 de mayo, de cohesión y calidad del Sistema Nacional de Salud; y arts. 2 y 6 de la Ley 12/2001, de 21 de diciembre, de Ordenación Sanitaria de la Comunidad de Madrid). De esta afirmación puede deducirse que no cabe diferencia de trato en relación con los pacientes que reciben asistencia sanitaria en función de la modalidad de gestión, afirmación que a nuestro juicio es perfectamente trasladable a todos los derechos que les asisten, entre ellos al de reclamar por las lesiones que sufran en sus bienes y derechos como consecuencia del funcionamiento de los servicios públicos.

A pesar de las bendiciones del TC al modelo, cierto que circunscritas a los términos del propio recurso, como de alguna forma justifica el TC a lo largo de la sentencia, y vinculadas al juicio de constitucionalidad y no de oportunidad, o de posibles consecuencias derivadas de la gestión del mismo, previamente el Auto de 11 de septiembre de 2013 del TSJ de Madrid concedió la suspensión cautelar de la Resolución de la Viceconsejería de Asistencia Sanitaria de la Consejería de Sanidad de 30 de abril de 2013, por la que se hizo pública la convocatoria para la licitación del contrato de servicios denominado «Gestión por concesión del servicio público de la atención sanitaria especializada correspondiente a los hospitales universitarios "Infanta Sofía", "Infanta Leonor", "Infanta Cristina", del Henares, del Sureste y del Tajo», en virtud del art. 62 de la Ley 8/2012, revés jurídico que trajo consigo que el proceso se paralizase al menos de momento ${ }^{22}$.

\section{Gestión a través de personificaciones jurídico-privadas}

Junto a las fórmulas indicadas de gestión indirecta, se han mantenido, aunque con menor impacto en el conjunto del sistema, fórmulas de gestión directa a través de personificaciones jurídico-privadas que, al no someterse a los rígidos controles del derecho público, han permitido una mayor flexibilidad en la gestión, y hasta épocas recientes un ocultamiento de la deuda de las administraciones públicas a las que se vinculaban. En primer lugar, hay que hacer referencia a las sociedades mercantiles

22 Posteriormente, se llega a la misma conclusión en más pronunciamientos de distintas Salas del TSJ de Madrid, lo que propició que tras el Auto de 27 de enero de 2014 por el que se rechaza el recurso de reposición contra el Auto de 13 de septiembre de 2013, el propio presidente de la Comunidad Autónoma anunciase la retirada del proceso privatizador. 
públicas como prestadoras de asistencia sanitaria. La técnica societaria ha sido sistemáticamente empleada por las administraciones públicas como una fórmula más para la organización de servicios y actividades públicas tradicionales, por su mayor flexibilidad y sobre todo por la posibilidad que ofrece de esquivar la aplicación del derecho administrativo. Sin embargo, en estos momentos, y en buena medida por los excesos de las administraciones en su utilización, de forma prácticamente unánime se considera que ha llegado el momento de reducir el sector público empresarial $^{23}$. Hasta la fecha las sociedades mercantiles públicas han tenido prohibido por el ordenamiento jurídico el desarrollo de facultades que implicasen el ejercicio de autoridad (DA duodécima de la LOFAGE y art. 85.3 de la LBRL antes de la reforma operada por la Ley 27/2013, de 27 diciembre), si bien no se descubre nada nuevo si se afirma que esta prohibición se incumplió de forma reiterada con consecuencias importantes para la posición jurídica de los ciudadanos, que se veían desprotegidos ante la inaplicación de las garantías que acompañan el ejercicio de poder por parte de las administraciones públicas ${ }^{24}$. Por ello no deja de llamar la atención que la nueva regulación de las sociedades mercantiles del sector público estatal, contemplada en la Ley 40/2015, de 1 de octubre, de régimen jurídico del sector público, permita que estas puedan asumir, aunque sea excepcionalmente, potestades públicas. Resulta difícilmente entendible que el legislador, tras proclamar en su preámbulo que apuesta por las personificaciones jurídicopúblicas, dificultando la creación de sociedades mercantiles, en el art. 113, permita «que excepcionalmente la ley pueda atribuirles el ejercicio de potestades administrativas». Se ignoran las causas que lo han motivado, el legislador no lo justifica ni lo motiva en su preámbulo y la doctrina ya ha tenido ocasión de dejar claro la confusión que genera ${ }^{25}$,

23 Informe Cora 2013. Preámbulos de las Leyes 15/2014, de 16 de diciembre, de racionalización del sector público, y 40/2015, de 1 de octubre, de régimen jurídico del sector público.

24 M. Cueto Pérez (2008), Procedimiento administrativo, sujetos privados y funciones públicas, Civitas, págs. 43 y ss.

${ }_{25}$ M. SÁNCHEZ Morón (2015), «La regulación del sector público institucional en el proyecto de Ley de régimen jurídico del sector público», en Documentación Administrativa, nueva época, 2; L. Martín Rebollo (2015), «Análisis de la nueva Ley de Régimen Jurídico del sector público», Aranzadi digital 1/2015. La primera dificultad viene dada por la distinción que el legislador maneja entre facultades que impliquen el ejercicio de autoridad y el ejercicio de potestades administrativas. Habría que preguntarse qué potestades administrativas no implican el ejercicio de autoridad y si realmente las categorías son distintas. Sin duda, el legislador y el Gobierno eran conscientes de que la prohibición contenida en la LOFAGE se incumplía en ciertas sociedades mercantiles y en lugar de buscar mecanismos para lograr su cumplimiento han optado por excepcionar su aplicación, lo cual a su vez resulta contradictorio con la voluntad manifestada y presente en el texto legal de limitar la expansión y el incremento de personificaciones-jurídico privadas. Si algún límite legal existía para detener dicha expansión era precisamente la prohibición del uso de potestades administrativas. 
si bien en el ámbito local esta previsión ya se había producido por parte del legislador ${ }^{26}$.

Por todo ello, la gestión de la asistencia sanitaria en el marco del SNS a través de empresas públicas no se consideró la opción más adecuada, para una actividad que se encuentra en las antípodas de lo que pueda ser la actividad mercantil o empresarial de las administraciones públicas. Si bien respecto a la asistencia sanitaria no se pueda decir que implique en sí misma el ejercicio de autoridad ${ }^{27}$, no podemos negar que sí implica un régimen de derechos, prestaciones y garantías que tienen un carácter claramente público y que en todo caso la actividad a desarrollar es un servicio público. A pesar de ello, como ya se ha señalado, la utilización de la forma societaria en el ámbito sanitario fue admitida en el Decreto Ley $11 / 1996$ y por la Ley $15 / 97$ y regulada por el RD 29/2000, de 14 de enero, para el ámbito del INSALUD ${ }^{28}$. Tempranamente se crearon por las CC.AA. empresas públicas destinadas a satisfacer algunos servicios como los servicios de emergencia ${ }^{29}$, pero también algún hospital, como en Andalucía el «Hospital Costa del Sol» (creado por la Ley 4/92, de 30 de diciembre, y sus Estatutos aprobados por Decreto 104/93, de 3 de agosto) ${ }^{30}$. Junto a Andalucía, donde se ha optado por asimilar estas empresas públicas a las entidades públicas empresariales del sector público estatal, la Comunidad de Madrid también

26 Por otro lado, no podemos olvidar que en el ámbito local la Ley 27/2013, en la nueva redacción que da al art. 85.3 de la Ley de Bases de Régimen Local, suprimió la prohibición de gestión de servicios públicos que implicasen ejercicio de autoridad para las sociedades mercantiles locales.

27 Se ha entendido por la doctrina que la prestación de asistencia sanitaria no implicaba ejercicio de autoridad, A. Menéndez ReXach (2008: 287). Sin embargo, a mi juicio, algunas actuaciones podrían generar ciertas dudas, sobre todo en lo que atañe a la relación de los pacientes del SNS con dichos centros (negación de acceso a las instalaciones hospitalarias, resolución de "procedimientos administrativos» y reclamaciones relativas a los derechos de los pacientes, incidentes con el personal de seguridad...).

28 Con anterioridad, el «Informe Abril» ya había abonado este terreno culpando de buena parte de las deficiencias en la prestación de servicios sanitarios al propio derecho administrativo y apostando clara y abiertamente por formas de gestión privadas.

29 Sistema de Emergencias Médicas, S.A. dependiente del Servicio Catalán de Salud o Emergencias Sanitarias dependiente del Servicio Andaluz de Salud.

30 La Ley 1/2011, de 17 de febrero, de reordenación del sector público de Andalucía configura a la Empresa Pública Hospital de la Costa del Sol como agencia pública empresarial, pasando a denominarse Agencia Pública Empresarial Sanitaria Costa del Sol, así como su objeto, que lo constituye ahora la coordinación de la gestión de los servicios sanitarios de las agencias públicas empresariales que se le adscriban, así como la gestión del Hospital Costa del Sol de Marbella (Málaga) y la de los Centros Hospitalarios de Alta Resolución que se establezcan en la provincia de Málaga. Por el Decreto 98/2011, de 19 de abril, se aprueban los estatutos de la misma. Igualmente, adscribe a la Agencia Pública Empresarial Sanitaria Costa del Sol a la Empresa Pública Hospital de Poniente de Almería, Empresa Pública Hospital Alto Guadalquivir y Empresa Pública Sanitaria Bajo Guadalquivir, que se han convertido a su vez en agencias públicas empresariales. 
ha optado por esta fórmula, con amparo en su Ley 12/2001, de 21 de diciembre, de Ordenación Sanitaria. Así al año siguiente, por medio de la Ley 13/2002, de 20 de diciembre, de Medidas Fiscales y Administrativas se crea la Empresa Pública Hospital de Fuenlabrada (art. 18), aprobándose inmediatamente sus estatutos por medio del Decreto 196/2002, de 26 de diciembre. Posteriormente, la Ley 4/2006, de 22 de diciembre, de Medidas Fiscales y Administrativas, creó seis hospitales más con esta fórmula. Al año siguiente, se crea la empresa pública Unidad central de radiodiagnóstico de la Comunidad de Madrid, por la Ley 7/2007, de 21 de diciembre, de Medidas Fiscales y Administrativas (art. 14). Sin embargo, el intento de dar el salto desde estas fórmulas a la gestión indirecta de la sanidad y el debate social generado en el intento, además del revés jurídico sufrido, han llevado a que la Ley 9/2015, de 28 de diciembre, de Medidas Fiscales y Administrativas, en su artículo 6 prevea la extinción de estas seis empresas públicas ${ }^{31}$. Esta decisión pone en evidencia cómo este tipo de personificaciones no pasan por su mejor momento como opción de gestión en el ámbito sanitario, probablemente en la línea ya señalada con carácter general para las sociedades mercantiles públicas, cuyo ámbito de actuación debería quedar relegado en exclusiva a las actividades que en su origen las legitimaron, actividades de carácter industrial y comercial.

En términos similares nos podemos pronunciar respecto a las fundaciones, las cuales también han adquirido protagonismo como alternativa organizativa jurídico-privada para los poderes públicos. Aunque la existencia de fundaciones públicas regidas por leyes especiales no era un fenómeno desconocido en nuestra Administración institucional, lo cierto es que a raíz de la posibilidad abierta en su día por la Ley 30/94, de 24 de noviembre, de Fundaciones y de Incentivos Fiscales, de creación de fundaciones por personas jurídico públicas, su utilización se ha generalizado como fórmula organizativa que permite de nuevo a las administraciones públicas esquivar en buena medida la aplicación del ordenamiento jurídico administrativo, lo que suscitó en su día un cierto debate ${ }^{32}$. La Ley 50/2002, de 26 de diciembre, de Fundaciones, con-

31 Con efectos de 30 de junio de 2016, se extinguen las empresas públicas creadas al amparo del artículo 12 de la Ley 4/2006, de 22 de diciembre, de Medidas Fiscales y Administrativas de la Comunidad de Madrid, pasando los hospitales gestionados por las empresas públicas extinguidas a formar parte del Servicio Madrileño de Salud como centros de atención especializada.

32 En este sentido, E. García de Enterría y T. Fernández Rodríguez (2015), Curso de Derecho Administrativo, vol. I, Thomson-Civitas, 17a , págs. 390-391 y 426; M. SÁnchez Morón (2015), Derecho Administrativo, Tecnos, págs. 424-426; J. Socías Camacho (2006), Fundaciones del sector público, Iustel, págs. 123 y ss.; F. Sosa WAGNer (2004), La gestión de los servicios públicos locales, Thomson-Civitas, 6 a edición, págs. 103-104; J. L. MarTínez López-MuñIz (2002), 
solidó abiertamente la posibilidad de aplicar la técnica fundacional al ámbito de la gestión pública. En la misma se reguló de forma separada las fundaciones del sector público estatal, en su capítulo XI, arts. 44-46, cuyo contenido trató de solventar algunas de las carencias de la normativa anterior y de las cuestiones e interrogantes planteados. Ahora, la Ley 40/2015, de 1 de octubre, de régimen jurídico del sector público, incluye dentro de la regulación de los diferentes entes a las fundaciones, arts. 128-136, derogando expresamente los arts. 44-46 de la Ley de Fundaciones del 2002 (Disposición derogatoria). La nueva regulación, aunque sigue principalmente lo dispuesto en los preceptos derogados, sí incluye algunas novedades, como la exigencia de que la constitución de una fundación del sector público en el ámbito estatal o la adquisición de este carácter de forma sobrevenida se realice por ley, mientras que en la anterior regulación bastaba la creación mediante acuerdo del Consejo de Ministros. Igualmente, se debe destacar que a diferencia de la flexibilización que se ha producido en relación con las sociedades mercantiles, las fundaciones del sector público siguen teniendo prohibido el ejercicio de potestades públicas y así se señala expresamente en el art. 128.2.

En el ámbito que nos ocupa, las fundaciones fueron expresamente permitidas por el Decreto Ley 11/96. Esta regulación se refería en principio a las fundaciones reguladas en la Ley 30/94, como personificaciones jurídico-privadas, sin embargo, la creación de las fundaciones para la gestión de los hospitales de Alcorcón y Manacor incluyó en su regulación elementos claramente de Derecho Público ${ }^{33}$, que desvirtuaban la configuración jurídico-privada, creando en palabras del profesor PIÑAR MAÑAS un régimen jurídico híbrido, privado y público, que no encajaba en el régimen de las fundaciones privadas ${ }^{34}$. Por este mismo camino avanzó la Ley 15/97, de 25 de abril, que sustituyó al Decreto Ley, dejando claro, tras el abierto debate producido tanto a nivel jurídico como social ${ }^{35}$, que el Sistema Nacional de Salud preserva su

«Fundaciones privadas del sector público: problemas de constitucionalidad», en XIII Congreso Italo-Español de Profesores de Derecho Administrativo, CEDECS, págs. 305 y ss.; J. L. BERMEJo LATRE (2000), «Las fundaciones privadas de iniciativa pública y la huida del Derecho Administrativo", en El Derecho Administrativo en el umbral del siglo XXI (coord. F. Sosa WAGNER), Tirant lo Blanch, págs. 935 y ss.; J. L. PIÑAR Mañas (1998), «Fundaciones constituidas por entidades públicas. Algunas cuestiones», en $R E D A, 97$, págs. 37 y ss.

33 Resolución de 21 de enero de 1997 de la Secretaría General de Asistencia Sanitaria, por la que se dio publicidad al Acuerdo del Consejo de Ministros de 22 de noviembre de 1996, por el que se autorizaba al INSALUD a constituir determinadas fundaciones y se aprobaban sus estatutos.

34 J. L. Piñar Mañas (2002), "Tercer sector, sector público y fundaciones», XII Congreso italo-español de Profesores de Derecho Administrativo, Cedecs, pág. 273.

35 En el momento de la publicación del Decreto Ley 10/96 se habló de privatización de la sanidad pública y en nuestro ámbito doctrinal se han publicado numerosos trabajos en 
condición de servicio público, lo cual a su vez constituía un obstáculo para que se utilizase en su gestión la figura de la fundación, tal y como se regulaba en el ámbito de la Ley $30 / 94^{36}$, pero la Ley 15/97 insiste en ello señalando que la gestión se podrá llevar a cabo a través de fundaciones $u$ otras entidades de naturaleza o titularidad pública. En el ámbito sanitario se amplían las posibilidades de su uso con la Ley 50/98, de 30 de diciembre, que en su art. 111 crea un nuevo tipo de fundaciones que constituyen una nueva categoría de organismos públicos, que por cierto no se contemplaba en la LOFAGE, pero que se someten en un buen número de cuestiones a normas administrativas ${ }^{37}$. Finalmente, se aprobó el ya mencionado RD 29/2000, de 14 de enero ${ }^{38}$, aplicable tanto a las fundaciones sanitarias del sector público constituidas al amparo del Decreto Ley 10/96 y de la Ley 15/97 (con fundamento a su vez en la Ley 30/94), como a las constituidas al amparo del art. 111 de la Ley 50/98 (que eran organismos públicos), regulando para todas ellas un régimen jurídico común. Por último, hay que señalar que la Ley 50/2002 expresamente excluyó de su aplicación a las fundaciones públicas sanitarias recogidas el artículo 111 de la Ley 50/1998, de 30 de diciembre, de Medidas Fiscales, Administrativas y del Orden Social, que seguirían rigiéndose por su normativa específica (DA tercera) y respecto a las fundaciones constituidas al amparo de la Ley 15/1997 establece que seguirían rigiéndose por su normativa específica, aplicándoseles los preceptos del capítulo XI con carácter supletorio (DA cuarta), dejando claro cómo estas categorías tenían un régimen ju-

\footnotetext{
relación con la cuestión, además de los ya citados, vid. J. Pemán Gavín (1996), «Hacia nuevas formas de gestión de los servicios sanitarios», en J. VelaRde FuerTEs (dir.), Reforma y liberalización económica: Los Decretos-Leyes de junio, Civitas, págs. 293-330, el mismo autor también en «Reflexiones en torno a la Ley General de Sanidad: ¿desarrollo o reforma?», en REDA, 97,1998, págs. 65-81; J. L. Bermejo Latre y O. Mir PuigPeLAT (1999), «Algunas notas sobre las primeras experiencias en la regulación de las fundaciones de iniciativa pública», en REDA, 104, págs. 575-593; L. Parejo, F. Lobo y M. Vaquer Caballería (coords.) (2001), La organización de los servicios públicos sanitarios, Marcial Pons.

36 J. L. PIÑAR MaÑas (2002: 271).

37 El art. 111 de la Ley 50/98 señalaba que las fundaciones públicas sanitarias son organismos públicos, adscritos al Instituto Nacional de la Salud, cuya constitución, modificación y extinción, así como la aprobación de sus correspondientes estatutos, serán aprobados por Acuerdo del Consejo de Ministros, a propuesta del ministro de Sanidad y Consumo. Su régimen de contratación respetará, en todo caso, los principios de publicidad y libre concurrencia, y se regirá por las previsiones contenidas al respecto en la legislación de contratos de las administraciones públicas, rigiéndose en lo no previsto en su regulación por lo dispuesto para las entidades públicas empresariales en la LOFAGE.

38 El RD 29/2000, de 14 de enero, fue impugnado por la Confederación Estatal de Sindicatos Médicos ante la jurisdicción contencioso-administrativa. En el mismo recurso se instaba el planteamiento de una cuestión de inconstitucionalidad en relación con el art. 111 de la Ley 50/98. El TS desestima el recurso y el planteamiento de la cuestión en su Sentencia de 27 de enero de $2003\left(\right.$ Sala $\left.4^{\mathrm{a}}\right)$, RJ 1073/2003.
} 
rídico diferenciado ${ }^{39}$. La jurisprudencia ha considerado que las fundaciones creadas en el ámbito sanitario conforme a la Ley 30/94, son verdaderos organismos públicos al igual que las fundaciones públicas sanitarias ${ }^{40}$, a pesar de ello, el ámbito sanitario ha sido un claro exponente del galimatías organizativo que la capacidad fundacional de las Administraciones ha generado. Al amparo de esta normativa se crearon varios hospitales ${ }^{41}$, hospitales que más tarde se han transferido a las CC.AA. ${ }^{42}$, manteniendo muchos de ellos su configuración como fundaciones del sector público (como el Hospital de Calahorra en La Rioja o el Hospital de Alcorcón en Madrid) o como fundación público sanitaria ${ }^{43}$, prestando en todos los casos asistencia sanitaria en el marco del Sistema Nacional de Salud.

39 E. M. Hernández Bejarano (2011), «La controvertida naturaleza jurídica de la fundación sanitaria Hospital de Manacor y la modificación del régimen jurídico de su personal», Temas Laborales, 109, págs. 207-224.

40 Así la sentencia de 28 de septiembre de 2005 de la AN (Sala de lo Contencioso-Administrativo), señala que «de la regulación expuesta se deduce que las fundaciones públicas sanitarias, entre las que se encuentra la Fundación Hospital de Alcorcón, son organismos públicos, adscritos al Instituto Nacional de la Salud, con personalidad jurídica propia, que aparecen diferenciados de las Instituciones sanitarias de la Seguridad Social dependientes del INSALUD»; el TSJ de Madrid, en la sentencia de 27 de enero de 2000, concluye que la Fundación Hospital Alcorcón «es una entidad de Derecho Público de naturaleza pública, cuyo régimen normativo no solo viene dado por la Ley 30/1994, sino sobre todo por disposiciones propias del Derecho estatutario de las Administraciones públicas». Respecto a las fundaciones públicas sanitarias, el TSJ de Galicia, en su sentencia de 10 de noviembre de 2010, señala que las fundaciones públicas sanitarias son «personas jurídicas pertenecientes al sector público, sin la consideración de Administraciones públicas».

41 Tras la aprobación de este RD se constituyeron dos nuevas fundaciones conforme a la Ley 30/94: la Fundación Hospital de Calahorra (Resolución de 11 de abril de 2000) y la Fundación Hospital de Son Llátzer (Resolución de 12 de junio de 2001).

${ }^{42}$ La Ley 12/2006, de 21 de diciembre, de Fundaciones de Galicia contempla a las fundaciones públicas sanitarias como una categoría diferenciada dentro de las fundaciones del sector público (DA segunda). Por otro lado, la Ley 8/2008, de 10 de julio, establece la integración de las fundaciones públicas sanitarias en el Servicio Gallego de Salud. En Galicia se mantienen en la actualidad la Fundación Pública Urgencias Sanitarias de Galicia 061, la Fundación Pública Gallega de Medicina Genómica y la Fundación Pública Centro de Transfusión de Galicia.

${ }^{43}$ La Ley de Fundaciones públicas sanitarias 1/2011, de 24 de febrero, de transformación de fundaciones del sector público sanitario de las Illes Balears y de determinación del régimen jurídico de las fundaciones públicas sanitarias transformó las fundaciones del sector público Hospital Son Llàtzer y Hospital de Manacor en fundaciones públicas sanitarias con personalidad jurídica propia, que tienen por objeto la gestión y la administración de los centros sanitarios Hospital Son Llàtzer y Hospital de Manacor, con el objetivo principal de que su personal pueda tener la condición de estatutario. Con anterioridad se había constituido como fundación pública sanitaria el hospital comarcal de Inca creado por Acuerdo de 17 de marzo de 2006 del Consejo de Gobierno Balear. 


\section{RESPONSABILIDAD PATRIMONIAL EN SUPUESTOS DE GESTIÓN PRIVADA}

\section{Responsabilidad de sociedades mercantiles y fundaciones por la prestación de asistencia sanitaria}

Expuestas de forma esquemática las fórmulas de gestión directa de las que se pueden servir las Administraciones sanitarias a la hora de prestar asistencia a los ciudadanos en el marco del SNS, procede ahora pasar a analizar el régimen jurídico de la responsabilidad patrimonial de dichas Administraciones cuando se causan lesiones a los particulares «por o con ocasión de la asistencia sanitaria». Hasta ahora el régimen de responsabilidad derivado de estas personificaciones había quedado clarificado a partir de lo dispuesto en la DA duodécima de la Ley 30/92, incorporada tras la reforma llevada a cabo por la Ley 4/99. El hecho de que incluyese dentro de la aplicación del régimen de responsabilidad patrimonial a «entidades, servicios y organismos del SNS» parecía tratar de abarcar todas las posibilidades organizativas de manera que se despejasen de forma definitiva las dudas y las controversias generadas en esta materia. De esta forma las reclamaciones habrían de seguir el procedimiento y el régimen jurídico de responsabilidad patrimonial regulado en la Ley 30/92 y en el RD 429/1993, de 26 de marzo, por el que se aprueba el Reglamento de los procedimientos de las administraciones públicas en materia de responsabilidad patrimonial, correspondiendo la competencia jurisdiccional al orden contencioso-administrativo. Por su parte, el RD 29/2000 no quiso sembrar dudas y resultó en su día un refuerzo a lo señalado en la propia Ley 30/92, ya que tras afirmar en el art. 3 que la gestión y administración de los centros, servicios y establecimientos sanitarios, en el ámbito del Instituto Nacional de la Salud, podrá llevarse a cabo a través de fundaciones constituidas al amparo de la Ley 30/1994, de 24 de noviembre, consorcios, sociedades estatales y fundaciones públicas sanitarias, así como mediante la constitución de cualesquiera otras entidades de naturaleza o titularidad pública admitidas en derecho, garantizando y preservando en todo caso su condición de servicio público, en su art. 35 establecía que las reclamaciones que formulen los ciudadanos encaminadas al resarcimiento de los daños y perjuicios causados por o con ocasión de la asistencia sanitaria prestada a través de las entidades recogidas en el artículo 3, se regirán por lo dispuesto en la Ley 30/1992 y en el Real Decreto 429/1993, de 26 de marzo. Tales reclamaciones se dirigirán por los interesados a la Administración responsable de los servicios sanitarios, contra cuya resolución cabe recurso contencioso-administrativo, pudiendo actuar los centros sanitarios, en 
virtud de su personalidad jurídica, como codemandados ${ }^{44}$. Por lo tanto, hasta ahora la circunstancia de que fuese un sujeto privado el llamado a prestar la asistencia sanitaria no modificó el régimen de responsabilidad patrimonial ni la competencia del orden jurisdiccional contenciosoadministrativo. La asistencia sanitaria prestada en el ámbito del SNS seguía teniendo la consideración de servicio público y, por lo tanto, los pacientes debían mantener un régimen jurídico común con independencia de la fórmula organizativa que hubiese elegido la Administración sanitaria para facilitar la asistencia. Así, lo ha venido entendiendo el TS que ha condenado a indemnizar a los Servicios de Salud de las diferentes CC.AA. por lesiones causadas a los pacientes derivadas de asistencia sanitaria prestada en centros constituidos por medio de alguna de estas personificaciones ${ }^{45}$.

Pero lo cierto es que en el resto de ámbitos de actuación administrativa el hecho de encontrarnos ante una fundación del sector público o ante una sociedad mercantil sí que genera dudas sobre su régimen de responsabilidad. En principio ni las sociedades mercantiles ni las fundaciones del sector público son Administraciones (art. 2 Ley 40/2015) y la aplicación del derecho administrativo a las personificaciones jurídico privadas siempre ha estado limitada, aunque con las excepciones derivadas de la titularidad pública (que afecta principalmente al régimen de contratación, de selección de personal, en materia presupuestaria). En el ámbito de la responsabilidad patrimonial se ha entendido que la jurisdicción competente respecto a la actuación de estas entidades instrumentales sería la jurisdicción civil, sin necesidad de seguir el procedimiento administrativo de reclamación ${ }^{46}$. La supresión de la DA duodécima de la Ley 30/92, por lo tanto, deja sin el principal fundamento legal la defensa del régimen de responsabilidad que hasta el momento se venía aplicando, dejando igualmente sin apoyo legal al art. 35 del RD 29/2000, el cual podría resultar insuficiente, pues como se ha

44 En este sentido, F.J. VILlar RoJAs (1996), La responsabilidad de las Administraciones sanitarias, Praxis, págs. 94 y ss.; O. Mir PuigPelat (2000), La responsabilidad patrimonial de la Administración sanitaria, Civitas, págs. 106 y ss.; M. Cueto Pérez (1997), La responsabilidad de la Administración en la asistencia sanitaria, Tirant Lo Blanch, 1997, págs. 205 y ss; también en «Responsabilidad patrimonial de la Administración en el ámbito sanitario», en T. QUINTANA López y A. B. CASARes Marcos (dirs.) (2013), Responsabilidad patrimonial de la Administración, Tirant lo Blanch, $2^{\circ}$ ed., tomo II, págs. 1025 y ss.

45 STS de 27 de diciembre de 2011(RJ 2012/3102), STS de 11 de mayo de 2010 (RJ 2010/4947) sobre responsabilidad de la Fundación Hospital Alcorcón. SSTSJ de Andalucía de 18 de enero de 2013, 5 de julio de 2013, 14 de marzo de 2014, 9 de septiembre de 2015 por las que se condena a la empresa pública Hospital Comarcal Costa del Sol a indemnizar junto al Servicio de Salud de Andalucía por daños causados con ocasión de la asistencia sanitaria.

46 M. Rebollo Puig (2013), «La reclamación de indemnización», en T. Quintana López y A. B. Casares Marcos (dir.) (2013: t. I, 105 y ss.). 
señalado no hacía otra cosa que aplicar lo dispuesto en la DA duodécima a todas las fórmulas de gestión que regulaba. Resulta evidente de todo lo expuesto que a nivel legal se ha producido un cambio, no sabemos si intencionado o no por parte del legislador, pues nada manifiesta en relación con esta supresión en los preámbulos de ninguna de las leyes, pero lo cierto es que en ausencia de la disposición derogada vuelve a ser necesario interpretar y deducir del conjunto normativo la necesidad de que se mantenga en los mismos términos el régimen de responsabilidad patrimonial derivado de la asistencia sanitaria cuando esta se preste en centros constituidos bajo la forma de una personificación jurídico privada. Por otro lado, el régimen de responsabilidad patrimonial tiene carácter básico de acuerdo con el art. 149.1.18 CE, lo que impediría la intervención de las CC.AA. en su regulación. El mayor argumento a favor de que no se produzca un cambio de criterio ni por parte de las administraciones ni por parte de los tribunales sería defender que las sociedades mercantiles o las fundaciones cuando prestan el servicio público de la asistencia sanitaria, lo hacen sometidas a un régimen jurídico público y que, por lo tanto, su responsabilidad debe someterse al procedimiento y al régimen jurídico de la responsabilidad patrimonial de acuerdo con las Leyes 39/2015 y 40/2015, de 1 de octubre, siendo igualmente competente la jurisdicción contencioso administrativa, como se ha defendido por la jurisprudencia ${ }^{47}$ y por algún sector doctrinal ${ }^{48}$. Además, hay que tener en cuenta que tanto la Ley 39/2015 como la Ley 40/2015 (art. 2.2 en ambos casos), al establecer su ámbito subjetivo de aplicación, entienden de forma novedosa que las entidades de derecho privado vinculadas o dependientes de las administraciones públicas quedarán sujetas a lo dispuesto en las normas que específicamente se refieran a ellas, y en todo caso, cuando ejerzan potestades administrativas. A mi juicio, la prestación de asistencia sanitaria en el marco del SNS podría entenderse que supone el ejercicio de ciertas potestades públicas y de ahí derivarse la aplicación del régimen de responsabilidad patrimonial de las administraciones públicas y la competencia del orden jurisdiccional contencioso-administrativo. Por supuesto, ello exigiría, como viene ocurriendo hasta aho-

47 Así lo ha señalado la importante STS de 8 de marzo de 2011, RJ 2011/2014, respecto a la Sociedad Estatal Correos y Telégrafos, entendiendo que «es el funcionamiento de los servicios públicos, o mejor dicho, que la lesión sea consecuencia de ese funcionamiento, lo que determina la responsabilidad patrimonial de la Administración pública». En el mismo sentido el Auto de la Audiencia Provincial de Barcelona de 18 de abril de 2008 que considera incompetente a la jurisdicción civil para resolver una reclamación de responsabilidad por la actuación de una sociedad mercantil perteneciente íntegramente a la Generalidad.

48 M. Rebollo Puig (2013: 105) señala que «esta solución tiene cierta lógica si estas entidades de Derecho privado causan el daño como consecuencia de una actividad de servicio público». Igualmente en M. Cueto Pérez (2008: 91 y 2013: 1041). 
ra, que se presentase la oportuna reclamación de responsabilidad ante los Servicios de Salud correspondientes y que estos la resolviesen sin derivar a los pacientes para que reclamen de forma exclusiva contra el centro. Lo contrario supondría volver a la ruptura del régimen jurídico aplicable y de la unidad jurisdiccional conseguida en la materia en un ámbito que presenta un número de reclamaciones muy elevado y en el que el legislador había afortunadamente resuelto la cuestión. Entender que una sociedad mercantil o una fundación del sector público sanitario que prestan asistencia sanitaria en el marco del SNS se someten a un régimen de responsabilidad de carácter privado implicaría aceptar que las reclamaciones de responsabilidad tendrían un devenir diferente en función de la forma de gestión utilizada, solución que a mi juicio no sería justa y no sería conforme a lo señalado en el art. 106.2 CE, sin perjuicio de que lo adecuado sería que la propia legislación sobre responsabilidad patrimonial lo estableciese de forma expresa. También como novedad, respecto a la responsabilidad de las administraciones por actividades sometidas a derecho privado en el art. 35 de la Ley 40/2015 sí se clarifica la cuestión incluso cuando se actúa mediante personificaciones. Así, se señala que cuando las administraciones públicas actúen, directamente o a través de una entidad de derecho privado, en relaciones de esta naturaleza, su responsabilidad se exigirá de conformidad con el régimen de responsabilidad patrimonial, incluso cuando concurra con sujetos de derecho privado o la responsabilidad se exija directamente a la entidad de derecho privado a través de la cual actúe la Administración o a la entidad que cubra su responsabilidad. Este precepto en todo caso puede reforzar la argumentación aquí defendida en el sentido de que si cuando la Administración actúa en relaciones sometidas a derecho privado el régimen de responsabilidad es público, con mayor razón habría que entender lo mismo cuando se trate de actividad sometida al derecho administrativo como ocurre con la prestación de asistencia sanitaria.

\section{Responsabilidad de la Administración por la gestión indirecta de la asistencia sanitaria}

A) Responsabilidad de la Administración derivada los servicios públicos concedidos

La responsabilidad de la Administración por servicios públicos concedidos ha sido una cuestión compleja y discutida a lo largo del tiempo, que sigue sin contar con una regulación satisfactoria en nuestra legisla-

Revista de Administración Pública

ISSN-L: 0034-7639, núm. 201, Madrid, septiembre-diciembre (2016), págs. 303-333

http://dx.doi.org/10.18042/cepc/rap.201.13 
ción. Tras la aprobación de las Leyes 39 y 40/2015, el texto de las normas se refiere por primera vez a la responsabilidad de los concesionarios y contratistas, aunque la regulación contemplada no parece que ponga fin a la complejidad de la cuestión. El primer tratamiento jurídico sobre la responsabilidad de la Administración por los daños producidos a los particulares, cuando se trate de un servicio público gestionado por un contratista, se recogió como es bien sabido en los arts. 121.2 y 123 de la Ley de Expropiación Forzosa, de 16 de diciembre de 1954, atribuyendo la responsabilidad al concesionario gestor del servicio, con la excepción de que el daño tuviese su origen en alguna cláusula impuesta por la Administración al mismo, de ineludible cumplimiento para este. El art. 123 obligaba al particular a dirigir la reclamación a la Administración titular del servicio, la cual resolvería tanto sobre la procedencia de la indemnización como sobre quién debía satisfacer el importe de la indemnización en función de los criterios ya señalados. Esta resolución dejaba abierta la vía contencioso-administrativa, tanto para el particular como para el concesionario en su caso ${ }^{49}$.

La doctrina mayoritaria interpretó estos preceptos entendiendo que el concesionario respondía de forma directa frente al lesionado ${ }^{50}$ y que la Administración solo respondería en los casos en los que se estuviese ante el supuesto excepcional señalado (cláusula impuesta por la Administración de ineludible cumplimiento), siendo competente la jurisdicción contencioso-administrativa para conocer de estos asuntos y debiendo ser exigida dicha responsabilidad no conforme al Código Civil ${ }^{51}$, sino conforme a la responsabilidad patrimonial de la Administración.

\footnotetext{
49 Algunos autores entienden que los preceptos de la LEF deben entenderse derogados por la legislación de contratos que sí regula el supuesto. Así, L. Martín Rebollo (2015), Leyes Administrativas, Manual y normas básicas, Thomson Reuters; L. Míguez Macho (1999), Los servicios públicos y el régimen jurídico de los usuarios, CEDECS, pág. 204; F. VILLALBA Pérez (2004), «Responsabilidad extracontractual del contratista por los daños causados a terceros en la ejecución del contrato», en REALA, 296-297, págs. 88-89.

50 R. Bocanegra Sierra (1978), «Responsabilidad de contratistas y concesionarios de la Administración Pública por daños causados a terceros», en REDA, 18, pág. 398; A. JiMÉNEZBlanco (1986), «Responsabilidad administrativa por culpa in vigilando o in omittendo», Poder Judicial, 2, págs. 127 y ss.; García De Enterría y Fernández Rodríguez (2013), Curso de Derecho Administrativo, tomo II, Thomson Reuters, $13^{\mathrm{a}}$ ed., pág. 388. En contra, consideró que la Administración respondía de forma directa también por los daños causados por los servicios concedidos, sin perjuicio de la posibilidad de repetir contra el concesionario la cuantía indemnizatoria, el profesor F. GONZÁlEz NAVARRo (1976), «Responsabilidad de la Administración por daños causados a terceros por el empresario de un servicio público», en Revista de Derecho Administrativo y Fiscal, 44-45. También han apoyado esta tesis I. Del Guayo Castiella (1990), «Responsabilidad de la Administración por el funcionamiento de los servicios públicos concedidos», en Actualidad Administrativa, 17, págs. 197 y ss; F. J. Villar RoJas (1996: 110 y ss.).

51 La jurisdicción civil, pese a lo dispuesto en el artículo 123 de la LEF, se declaró competente en numerosas ocasiones (STS de 22 de noviembre de 1985, RJ 1985/5632; 2 de febrero de 1987, RJ 1987/673; 19 de diciembre de 1987, RJ 1987/9589; 10 de abril de 1988, RJ 1988/3116).
} 
Con ello se conseguía que fuese cual fuese la forma de gestión de un determinado servicio público la responsabilidad patrimonial tendría un tratamiento unitario conforme a lo dispuesto en el artículo 106.2 de la $\mathrm{CE}$, ya que tanto en un caso como en otro, estaría presente el funcionamiento de un servicio público ${ }^{52}$. Solamente en aquellos casos en los que se produjese la insolvencia del gestor del servicio público, cabría entender que la Administración indemnizase de forma subsidiaria a los particulares ${ }^{53}$.

La Ley 30/92 incomprensiblemente no entró a tratar esta materia ${ }^{54}$, como tampoco lo hizo la Ley 4/99, de 13 de enero, de reforma de la misma, a pesar de su clara intención de agotar el régimen de responsabilidad patrimonial de las administraciones públicas y de lograr un tratamiento uniforme, tanto desde el punto de vista del régimen jurídico aplicable como desde el procedimental y procesal. Sí lo hizo el Reglamento regulador del procedimiento de las administraciones públicas en materia de responsabilidad patrimonial, aprobado por Real Decreto 429/93, de 26 de marzo (RRP) en su art. 1.3 al señalar que se seguiría el procedimiento de responsabilidad patrimonial para determinar la responsabilidad de las Administraciones por daños y perjuicios causados a terceros durante la ejecución de contratos, cuando fuesen consecuencia de una orden directa e inmediata de la Administración o de los vicios del proyecto elaborado por ella misma, con arreglo a la legislación de contratos de las administraciones públicas. Sin embargo, la redacción de este artículo del Reglamento sembró ciertas dudas, en cuanto que parece dejar entrever que solo en los supuestos en los que la responsabilidad

52 En este sentido, M. Rebollo Puig (1990), «Servicios públicos concedidos y responsabilidad de la Administración: imputación o responsabilidad por hecho de otro (Comentario a la STS de 9 de mayo de 1989)», en Poder Judicial, 20, pág. 28; E. Carbonell Porras (1994), "Algunas reflexiones sobre la empresa pública como concesionaria de servicios públicos: régimen de responsabilidad», en Administración Instrumental, Libro Homenaje al Profesor Clavero Arévalo, Civitas, pág. 1076; R. Bocanegra Sierra (1994), «La responsabilidad civil de los concesionarios y contratistas de la Administración por daños causados a terceros», en Documentación Administrativa, 237-238, pág. 217.

53 Defender la responsabilidad directa de la Administración probablemente nos llevaría a la misma situación que existe frente a los empleados públicos, pues a pesar de que la Administración viene obligada a ejercer la acción de regreso, en la inmensa mayoría de los supuestos esta obligación no se ejercita, con el resultado de que en último término siempre es la Administración quien indemniza. En este sentido, S. Muñoz Machado (1992), La responsabilidad concurrente de las Administraciones Públicas, Civitas, pág. 135; M. Beladiez Rojo (1997), Responsabilidad e imputación de daños por el funcionamiento de los servicios públicos, Tecnos, pág. 354; M. Rebollo Puig (2013).

54 L. Martín Rebollo (1994), "La responsabilidad patrimonial de las Administraciones Públicas en España: estado de la cuestión, balance general y reflexión crítica», Documentación Administrativa, 237-238, pág. 12; M. Beladiez Rojo (1997); M. Cueto Pérez (2000), «Avances y retrocesos en la responsabilidad de las Administraciones públicas tras la reforma de la Ley 30/92», en RAP, 152, pág. 270. 
correspondiese a la Administración se seguiría el procedimiento establecido en dicho Reglamento. ¿Qué ocurriría en el resto de supuestos, cuando la responsabilidad correspondiese al contratista? A mi juicio, tanto en uno como en otro caso, la opción más adecuada sería defender un único procedimiento de responsabilidad patrimonial, un único régimen jurídico aplicable y un solo orden jurisdiccional competente ${ }^{55}$.

En cuanto a la regulación de la responsabilidad del contratista, contenida en la normativa sobre contratación pública, hay que señalar que esta tampoco ha sido excesivamente afortunada. Tanto la Ley 13/95, de 18 de mayo, de Contratos LCAP $^{56}$, como posteriormente el Texto refundido del año 2000, aprobado por el Decreto Legislativo 1/2000, de 16 de junio $^{57}$, se separaron de la regulación fijada en la LEF, apuntando hacia una responsabilidad del contratista diferenciada de la responsabilidad patrimonial de la Administración. La Ley de Contratos del Sector Público de 2007 y ahora su TRLCSP mantienen esta posición en su art. 214 (para el contrato de gestión de servicios públicos en el art. 280). El contratista tiene la obligación de indemnizar todos los daños y perjuicios que se causen a terceros como consecuencia de la ejecución del contrato. Solo cuando los mismos se hayan ocasionado como consecuencia inmediata y directa de una orden de la Administración o sean consecuencia de los vicios del proyecto elaborado por ella misma en el contrato

$55 \mathrm{Y}$ en este sentido se pronunció en su día el Consejo de Estado en el dictamen emitido en relación con este Reglamento, Dictamen de 11 de febrero de 1993, en el que indicó que la redacción del precepto no era excesivamente afortunada y que podría generar confusión. Señalando que a su juicio todas las formas de gestión de los servicios públicos directas o indirectas deberían seguir el procedimiento regulado en el Reglamento. F. Villalba Pérez (2004: 101); M. Rebollo Puig (2013: 115-116).

56 En un primer momento la Ley 13/95, de 18 de mayo, de Contratos LCAP señalaba en el artículo 98 la obligación del contratista de indemnizar todos los daños y perjuicios, que se causasen a terceros como consecuencia de las operaciones que requiriese la ejecución del contrato, sin embargo, cuando esos daños fuesen consecuencia inmediata y directa de una orden de la Administración sería ésta la responsable.

Respecto a este precepto, habría que resaltar, en primer lugar, el carácter facultativo con el que la Ley establecía la reclamación ante el órgano de contratación, frente al carácter obligatorio del artículo 123 de la LEF, y en segundo lugar, se señalaba que la reclamación ante el órgano de contratación interrumpía el plazo de prescripción de la acción civil, con lo cual parecía que la Ley consideraba que los terceros que ejerciesen su reclamación frente al contratista debían hacerlo ante la jurisdicción civil y de acuerdo con la normativa del CC. Por su parte, el apartado 4 de ese artículo 98 de la LCAP de 1995 establecía que la reclamación de los terceros se formularía de acuerdo con el procedimiento establecido en la legislación aplicable (la civil en los casos que corresponda responder al contratista y la administrativa en los que la responsabilidad sea de la Administración). Así fue interpretado dicho precepto, vid. C. HorgÚE BAENA (1998): "La responsabilidad del contratista por daños causados a terceros en la ejecución de los contratos administrativos", RAP, no 147; F. Villalba Pérez, F. (2004): op. cit., pág. 88-89.

$57 \mathrm{El}$ art. 97 del TRLCAP señalaba sustancialmente lo mismo que la LCAP, aunque con alguna matización. La más importante venía dada por el hecho de que en el apartado 3 del mismo, ya no se hacía referencia a la acción civil, sino que simplemente se decía "Que el ejercicio de esta facultad interrumpe el plazo de prescripción de la acción". 
de obras o en el de suministro de fabricación será esta la responsable frente a quien haya sufrido las lesiones. Los terceros podrán dirigirse a la Administración (órgano de contratación) para que oído el contratista se pronuncie sobre a cuál de las partes contratantes corresponde la responsabilidad de los daños. También se señala la interrupción del plazo de prescripción de la acción y que la reclamación de los mismos se formulará, en todo caso, conforme al procedimiento establecido en la legislación aplicable a cada supuesto.

Y con esta regulación vigente, la Ley 40/2015, de 1 de octubre, señala en su art. 32.9 lo siguiente: «Se seguirá el procedimiento previsto en la Ley de Procedimiento Administrativo Común de las Administraciones Públicas para determinar la responsabilidad de las Administraciones Públicas por los daños y perjuicios causados a terceros durante la ejecución de contratos cuando sean consecuencia de una orden inmediata y directa de la Administración o de los vicios del proyecto elaborado por ella misma sin perjuicio de las especialidades que, en su caso, establezca el Real Decreto Legislativo 3/2011, de 14 de noviembre, por el que se aprueba el texto refundido de la Ley de Contratos del Sector Público». Como fácilmente se puede comprobar, este precepto reproduce lo hasta ahora recogido en el Reglamento regulador del procedimiento de responsabilidad patrimonial, lo que genera las mismas dudas que el reglamento generó en su día, con el agravante de que ahora se recoge en la Ley ${ }^{58}$. Ante esta novedad legislativa debemos reconocer que el problema del procedimiento a seguir y de la jurisdicción competente dista mucho de estar claro, sin embargo, creemos que la lógica del sistema ha de prevalecer y ella nos lleva a seguir defendiendo la conveniencia de que la responsabilidad del contratista se solvente conforme al régimen administrativo de la responsabilidad y ante la jurisdicción contencioso administrativa, en otro caso, corremos el riesgo de que se produzcan sentencias contradictorias sobre supuestos idénticos y, por otro lado, podría dar lugar a resoluciones injustas, como ya se ha señalado en relación con la responsabilidad de las personificaciones jurídico privadas.

Otro problema que surgirá para el particular será determinar en un primer momento a quién corresponde la obligación de indemnizar. Conforme a la LEF esa duda la resolvía el órgano de contratación ante el que en todo caso había que presentar la reclamación, sin embargo, en estos momentos el carácter facultativo con que el artículo 214.3 de la TRLCSP mantiene este requerimiento hace que el particular pueda

58 Cuestión criticada en el Dictamen del Consejo de Estado 275/2015 sobre el anteproyecto de Ley.

Revista de Administración Pública

ISSN-L: 0034-7639, núm. 201, Madrid, septiembre-diciembre (2016), págs. 303-333

http://dx.doi.org/10.18042/cepc/rap.201.13 
optar por uno u otro procedimiento con alto número de posibilidades de equivocarse, abriéndose la alternativa de la vía contencioso-administrativa, solo en el caso de que el mismo se produzca. Idéntico escollo se produce ahora con la redacción del nuevo art. 32.9 de la Ley 40/2015, si bien es cierto que la vía que mejor protege al particular lesionado es la de reclamar ante la Administración titular del servicio ${ }^{59}$. Además, una reciente línea jurisprudencial, ante el elevado número de supuestos en los que la Administración no da respuesta al requerimiento efectuado por el particular, viene condenando a la Administración en materia de servicios públicos concedidos ${ }^{60}$. Lo único que no ofrece dudas en estos momentos es que la Administración no puede ser demandada ante la jurisdicción civil y también que si se la demanda junto al concesionario se deberá residenciar la demanda ante la jurisdicción contenciosoadministrativo (art. 2 e LJCA y art. 9.4 LOPJ). Sin embargo, nada impide que el concesionario sea demandado ante la jurisdicción civil cuando la reclamación se dirija contra él a título individual, dando de nuevo lugar a que supuestos de responsabilidad por funcionamiento de los servicios públicos acaben en manos de la jurisdicción ordinaria. Del apartado 4 del art. 214 del TRLCSP, y ahora también del art. 32.9 de la Ley 40/2015, parece deducirse que hay un procedimiento diferente y una legislación diferente en función de quién esté llamado a responder, la Administración o el contratista, la primera conforme a la regulación administrativa y ante la jurisdicción contencioso administrativa y el segundo conforme al CC y ante la jurisdicción civil, a pesar de que resulte poco adecuado que se siga manteniendo la doble vía. El contratista, al asumir la gestión del servicio público, lo hace en los mismos términos que lo haría la Administración contratante y así lo ha reconocido en algunos casos el Consejo de Estado $^{61}$ y también la jurisprudencia ${ }^{62}$. La doctrina, por

59 J. SUAY Rincón (2002), «La responsabilidad patrimonial de los contratistas y de la Administración por el funcionamiento de los servicios públicos», en Estudios Jurídicos a la memoria de José María Lidón, Bilbao, Universidad de Deusto, págs. 1311 y ss.

${ }^{60}$ Entre otras, SSTS 22 de mayo de 2007 (RJ 4954) y 11 de febrero de 2013 (RJ 2084).

61 Así el Consejo de Estado, en su dictamen 778/2004, de 20 de mayo, señala que: "No empece la pertinencia de esta declaración de responsabilidad la previsión contenida en el art. 97.1 de la Ley de Contratos de que será “obligación del contratista indemnizar todos los daños y perjuicios que se causen a terceros como consecuencia de las operaciones que requiera la ejecución del contrato", puesto que este precepto no comporta la exoneración de responsabilidad de la Administración frente al particular lesionado. Antes, al contrario, ésta está obligada frente al perjudicado, si bien, por aplicación del referido precepto, el montante de la indemnización corre de cuenta del contratista». En otros, incluso opta por recoger la responsabilidad directa de la Administración (Dictamen 986/2008), considerando, además, que procede ejercer la acción de repetición contra la empresa.

62 Así, en la STS de 25 de febrero de 1998 (RJ 1998/1810) se señala que la responsabilidad de un concesionario en la gestión del servicio es una cuestión de «carácter estrictamente administrativo», "que afecta a la organización de un servicio y a su gestión, cuyo directo control 
su parte, igualmente ha formulado nuevos planteamientos, defendiendo que la responsabilidad del contratista en lo que se refiere a la prestación del servicio objeto del contrato ha de ser objetiva ${ }^{63}$. Todo lo señalado hasta aquí adquiere una especial importancia en el ámbito sanitario a raíz de la supresión de la Disposición Adicional $12^{a}$ de la Ley 30/92.

B) La responsabilidad patrimonial en supuestos de gestión indirecta de la asistencia sanitaria

En el ámbito de la asistencia sanitaria, en cambio, sí que hasta ahora estaba resuelta la cuestión al menos para el supuesto de los conciertos sanitarios en la tantas veces mencionada DA duodécima de la Ley, siendo el único caso de regulación expresa sobre la responsabilidad de un contratista de la Administración en la prestación de un servicio público al margen de la legislación sobre contratos públicos, probablemente por el hecho de que el número de reclamaciones en este ámbito es muy numeroso y también por la especial sensibilidad de los ciudadanos en relación con la asistencia sanitaria. En el caso de los conciertos, la cuestión quedaba claramente resuelta aplicándose a los mismos el régimen jurídico de la responsabilidad patrimonial, el procedimiento de reclamación regulado en el RD 429/93, de 26 de marzo, y atribuyéndose la competencia para su revisión jurisdiccional al orden contencioso administrativo. Así cualquier reclamación presentada por los lesionados en el ámbito del SNS debería compartir el mismo régimen jurídico y contar con idénticas garantías. Por ello, en este ámbito, a pesar de lo dispuesto en la legislación de contratos, las reclamaciones se han venido presentando contra los Servicios de Salud de las CC.AA. con independencia de la forma de gestión. Sin embargo, el uso de nuevas fórmulas de gestión indirecta, con posterioridad a la aprobación de esta disposición, sí que sembró ciertas dudas, por el hecho de que la Ley hiciese referencia ex-

sigue correspondiendo a quien ostenta la titularidad del servicio, por lo que no son los Tribunales Civiles, los órganos jurisdiccionales competentes para conocer de los conflictos que pudieran surgir, sino que al tratarse de una cuestión en que la Administración ha de actuar en el ámbito de sus competencias, no se trata de una relación estricta de carácter contractual entre el concesionario y usuario, sino de una relación que afecta a la prestación del servicio público». Incluso la Sala Primera del TS ha atribuido la competencia jurisdiccional al orden contencioso administrativo en algún supuesto, así la STS 20 de febrero de 2003 (RJ 2003/1179) respecto a una reclamación de un particular a un contratista por un contrato de obras.

63 M. Beladiez Rojo (1997: 223); F. Villalba Pérez (2004: 99); A. B. Casares Marcos (2013), «Responsabilidad patrimonial de la Administración por daños causados a terceros con motivo de la ejecución de contratos», en La responsabilidad de la Administración Pública..., op. cit., págs. 1486 y ss. 
presa solamente a la modalidad del concierto y por la regulación contenida en la legislación de contratos públicos ${ }^{64}$. Con apoyo en el régimen jurídico contemplado en el TRCSP, se consideraría que la previsión de la DA duodécima de la Ley 30/92 sería una excepción al régimen general de responsabilidad de los contratistas regulada en la legislación de contratos, que no podría ser interpretada de forma extensiva. Con la DA duodécima todavía vigente, también es cierto que podría ser planteada una interpretación que entendiese que el contenido de la misma debía aplicarse al resto de modalidades de gestión indirecta. En primer lugar, la regulación contenida en la DA duodécima claramente se dicta para clarificar el régimen jurídico de la responsabilidad para los daños y perjuicios causados por o con ocasión de la asistencia sanitaria, por lo que el legislador trató de abarcar toda la asistencia prestada por el INSALUD (en un momento en el que todavía no se habían concluido las transferencias competenciales a todas las CC.AA.). Junto a las personificaciones privadas, se incluyen los centros concertados, única modalidad de contrato de gestión de servicio público que se utilizaba en el momento de aprobación de la Ley 4/99. Por lo tanto, el hecho de que no se mencionasen expresamente otras modalidades de gestión no avalaría que ante una misma categoría contractual (el contrato de gestión de servicio público), una modalidad (el concierto) tuviese un régimen de responsabilidad y las restantes otro (parecería poco coherente). Finalmente, resulta difícil defender que los pacientes puedan tener un régimen de responsabilidad diferente, en función de la modalidad de gestión por la que opte la Administración en el ejercicio de su potestad de organización de la asistencia sanitaria, porque ello sería en último término contrario a la garantía patrimonial que recoge el art. 106.2 de la CE a favor de los particulares cuando sufran lesiones como consecuencia del funcionamiento de los servicios públicos y crearía una situación de desigualdad que no sería admisible conforme a lo expuesto por el TC en su sentencia 84/201565.

La jurisprudencia reciente en estos supuestos es clara y considera que la asistencia sanitaria prestada en un centro concertado vincula a la Administración sanitaria pública, que será en último término responsable, ya que se considera que tiene condición de representante o mandatario de la sanidad pública en el ejercicio de sus funciones (SSTS de 23

\footnotetext{
64 J. CANTERo Martínez (2009), «La responsabilidad patrimonial por actuaciones sanitarias realizadas por contratistas o concesionarios de la administración en los dictámenes del Consejo Consultivo de Castilla-La Mancha», en Revista Jurídica de Castilla-La Mancha, 47, págs. 199 y ss. L. Tolivar Alas (2007: 54 y ss.). D. Larios Risco y V. Lomas Hernández (2007: 309); M. Domínguez Martín (2011: 128).

65 F.J. Villar Rojas (1996: 84. y ss.); O. Mir Puigpelat (2000: 124-138 y 154 y ss.).
} 
abril de 200866, 30 de noviembre de 201067, 19 de mayo de 201168, 30 de abril de $\left.2013^{69}\right)$. También hay que señalar que la jurisdicción contencioso administrativa ha venido conociendo hasta la fecha de las reclamaciones por responsabilidad patrimonial derivadas de la asistencia sanitaria prestada en hospitales gestionados mediante la fórmula de concesión de servicio público (SSTSJ de Valencia de 2 de octubre de 2014 y de 11 de mayo de 2015 y STSJ de Madrid de 11 de abril de 2014). Hasta ahora la tramitación de las reclamaciones por responsabilidad derivada de la asistencia sanitaria prestada en el marco del SNS era pacífica y la aplicación de la DA duodécima de la Ley 30/92 (en la que se apoyan la mayor parte de los pronunciamientos) había facilitado la clarificación del sistema y permitido la unidad del procedimiento, del régimen jurídico y de la jurisdicción competente. Por todo ello, cuesta entender las razones que han llevado al legislador a suprimir su contenido del articulado de las Leyes 39/2015 y 40/2015. Se podría entender que asentado el sistema se ha considerado que ya no procedía una mención específica a las reclamaciones de responsabilidad en un determinado ámbito de actuación administrativa, pero también es cierto que si el contenido de la Ley se ha alterado es porque ha tenido que haber una voluntad del legislador en ese sentido. Lo conveniente hubiese sido que la nueva normativa hubiese procedido a actualizar el precepto, más si tenemos en cuenta que las previsiones que se incorporan sobre la responsabilidad de los concesionarios y contratistas pueden generar nuevas dudas, dudas que hasta ahora había sido posible disipar con el apoyo que ofrecía la DA eliminada.

Sin embargo, el temor expuesto no es infundado, de hecho, la quiebra de la unidad del régimen de responsabilidad ya se ha producido en el ámbito sanitario en relación con las reclamaciones por la asistencia sanitaria prestada a los pacientes que reciben su cobertura sanitaria por las mutualidades de funcionarios a través de centros concertados. En estos casos, la jurisprudencia venía entendiendo que la reclamación podía dar lugar a la responsabilidad de la Administración y así lo afirmó en diferentes sentencias (entre otras, SSTS de 20 de febrero de $2007^{70}$, 24 de mayo de $2007^{71}$ y 3 de julio de $2003^{72}$ ), considerando que al tratarse de una asistencia sanitaria prestada en el ámbito de un concierto,

\footnotetext{
66 RJ 2008/2731.

67 RJ 2010/8765.

68 RJ 2011/4465.

69 RJ 2013/4058.

70 RJ 2007/843.

71 RJ 2007/5088.

72 RJ 2003/5431.
} 
no excluía la existencia de una posible responsabilidad patrimonial de la Administración y además entendía que la DA duodécima de la Ley 30/92 venía a sujetar a la revisión de la jurisdicción contencioso-administrativa, de manera unitaria, las reclamaciones por daños y perjuicios causados por o con ocasión de la asistencia sanitaria en el ámbito del SNS. Sin embargo, el hecho de que la LCSP del año 2007 estableciese en su DA vigesimotercera que «los conciertos que tuviesen por objeto la prestación de servicios de asistencia sanitaria y farmacéutica y que, para el desarrollo de su acción protectora, celebrasen la Mutualidad de Funcionarios Civiles del Estado y el Instituto Social de las Fuerzas Armadas con entidades públicas, entidades aseguradoras, sociedades médicas, colegios farmacéuticos y otras entidades o empresas, cualquiera que sea su importe y modalidad, tendrían la naturaleza de contratos de gestión de servicio público regulándose por la normativa especial de cada mutualidad y, en todo lo no previsto por la misma, por la legislación de contratos del sector público» (con el mismo contenido se recoge ahora en la DA vigésima del TRLCSP), llevó a que la jurisprudencia reconsiderase su posición, a mi juicio sin justificación suficiente para ello, vigente como estaba la DA duodécima de la Ley 30/92, ya que los conciertos sanitarios, aunque con propia regulación, siempre han constituido una modalidad dentro de los contratos de gestión de servicios públicos. Las sentencias de la Audiencia Nacional de 16 de febrero de 201173, 9 de marzo de $2011^{74}, 4$ de mayo de $2011^{75}, 15$ de junio de $2011^{76}, 24$ de octubre de $2011^{77}, 10$ de diciembre de $2014^{78}$, entienden que con la previsión hecha en la legislación de contratos, la responsabilidad derivada de estos conciertos pasa a regirse por las previsiones sobre responsabilidad del contratista, considerando que la legislación aplicable es la contenida en el CC sobre responsabilidad civil ${ }^{79}$.

Por todo ello, resulta especialmente preocupante la situación que se producirá a partir de la entrada en vigor de las Leyes 39 y 40/2015, ya

73 RJ 2011/68293.

74 RJ 201194844.

75 RJ 2011/184913.

76 RJ 2011/245755.

77 RJ 2011/406846.

78 RJ 11029.

79 Este asunto ha estado acompañado de una gran conflictividad judicial, la aplicación de esta interpretación se extendió incluso a supuestos que se habían producido sin que hubiese entrado todavía en vigor la DA vigesimotercera de la LCSP de 2007, lo que acabó en varias sentencias del TS dictadas para la unificación de doctrina en las que claramente se consideró que a los casos anteriores no se podía aplicar, dando por buena, sin embargo, su aplicación a los supuestos posteriores a la entrada en vigor de la disposición, STS 18 de octubre de 2011 (RJ 2012/1207) y 9 de diciembre de 2015 ( RJ 1016/149). 
que a partir de ese momento desaparecerá el apoyo que brindaba la DA duodécima de la Ley 30/92, para seguir defendiendo la argumentación expuesta. Si se sigue la estela seguida en relación con los conciertos de la mutuas funcionariales, podría ocurrir que los Servicios de Salud de las CC.AA. empezasen a entender que las reclamaciones presentadas por los daños causados como consecuencia de la asistencia sanitaria prestada a través de centros concertados o empresas concesionarias deberían ser presentadas directamente ante ellas, correspondiendo a la jurisdicción civil pronunciarse sobre las mismas. Esto supondría un claro retroceso en las garantías de los pacientes que, como se viene reiterando, deben ser las mismas con independencia de la forma de gestión utilizada. El tiempo dirá si finalmente este es el resultado de la supresión del contenido de la DA duodécima de la Ley 30/92. 
